of stress by the decrement of sectional area of specimen due to fatigue crack.

(4) The corrosion effects $k$ are almost equivalent on plane bending and rotary bending, which have been indicated by one of the authors. It may be suggested to be the same value of $k$ on both of them at an early stage of fatigue.

(5) The transition temperature will be influenced by the shape of surface on which the fatigue cracks developed. Kanazawa(c) has indicated the effect of notch shape on the transition temperature. In his paper the transition temperatures on 2 specimens notched as shown in Append-Fig. 2, almost

(c) T. Kanazawa: Jour. Japan Soc. Naval Arch., No. 91 (1955), p. 55 . coincided when $c=(a+b) / 2$. The four corners of squared specimen are slightly rounded to avoid the stress concentration. The trace of fatigue crack was made as shown in Append-Fig. 3 (a), still the stress concentration occured in crack of above $1 \mathrm{~mm}$ appearing on side of specimen. The trace looked as shown in Append-Fig. 3 (b) in crack of shorter length. Introducing the mean value of crack length appearing on side and the shortest length of central part on the fractured surface in the former, and the crack length appearing on side itself in the latter, the relationships between transition temperature and crack length are dealt with in this paper. (4) This is the same as closure (1) for J. Hoshino.

620. 178. 38:539.43.019. $1: 620.194 .8$

\title{
The Effect of Atmosphere on the Frequency Effect in the High Temperature Fatigue of a Carbon Steel ${ }^{*}$
}

\author{
By Kichiro ENDo**
}

The atmospheric effect on the frequency effect was studied in the high temperature fatigue of a carbon steel by using dried town gas as an inert environment. At $550^{\circ} \mathrm{C}$, the fatigue strength was higher in gas than in air in the long life test under low stress levels owing to the reduction of corrosion fatigue effects by high temperature oxidation. At $400^{\circ} \mathrm{C}$, the effect of gas was hardly found on fatigue strengths. Considerations were made on the frequency effect in stress $\tau$-rupture time $t$ curves and in plastic strain amplitude $\gamma_{p}$-cycles to rupture $N$ curves. The relation of $\gamma_{p} N^{0.44}=K$ was obtained under various cyclic frequencies and various temperatures, covering a wide range of $N$. The value of $K$ was larger for lower frequency than for higher frequency, the effect of frequency increasing at higher temperature. The deviation was found after long time in the air, due to corrosion fatigue by high temperature oxidation.

\section{Introduction}

There heve been some studies ${ }^{(1)(2)}$ on the effect of cyclic frequency on fatigue strengths at elevated temperatures, but these were carried out in air and the effect of atmosphere was not considered. The author indicated in the previous paper ${ }^{(3)}$, that the oxidation by high temperature atmosphere had an effect of corrosion fatigue and the $S-N$ curve took a considerably different figure from that in air when carbon steels were tested at $550^{\circ} \mathrm{C}$ in a non-oxidiz-

* Received 16th December, 1960.

** Professor, Faculty of Engineering, Kyoto University, Sakyo-ku, Kyoto. ing environment. The effect of atmosphere on high temperature fatigue becomes a focus of researches. Other papers than those referred to in the author's previous paper should be added to the references ${ }^{(4)}$ (7) on this problem. Cazaud ${ }^{(8)}$ has also considered that the oxidation process is an important factor for continuous reduction of stress with disappearance of the ordinary horizontal portion of $S-N$ curve at elevated temperatures.

Consequently, it may be assumed that the influence of corrodibility of environments is included in the frequency effect of high temperature fatigue. The author has carried out high temperature fatigue tests of a carbon steel, varying cyclic frequency 
under torsional moments in air and also in town gas to reduce the air oxidation. These results are rearranged by repeated plastic strains in this paper, and are investigated by comparing with previous studies to make some contributions in the field of thermal fatigues.

\section{Fatigue tests}

The test material is $0.39 \% \mathrm{C}$ plain carbon steel whose chemical compositions and mechanical properties at the room temperature are shown in Table 1. The shape of test piece is shown in Fig. 1.

The testing machine and testing methods are the same as described in the previous paper $^{(3)}$. The torsional moments given to test pieces are estimated by elastic deformation of the torsion bar connected to the one end of the test piece, whose other end is twisted repeatedly by a crank mechanism. When the moment is measured statically as in usual tests at room temperature, the moment is shortly reduced because of creep deformation of test pieces and can not be assessed at elevated temperature. And a device of electric contacts composed of platinum contact points and micrometers is set to measure the moment during a run at the normal velocity. Accordingly, stress values shown later are not avoided to take fractions. The strain amplitude is calculated from the deformation of test piece which is measured in terms of the difference of oscillating angles between both chucking elements. No effect of frequency due to inertia of machine parts is detected on the magnitude of stresses by inspection under up to 2000 c.p.m.

In the early stage of tests, especially under high stresses and high temperatures, the moments vary slightly because of the changing of the material properties of test pieces, and the stresses discussed later are taken as the nominal stresses calculated elastic-

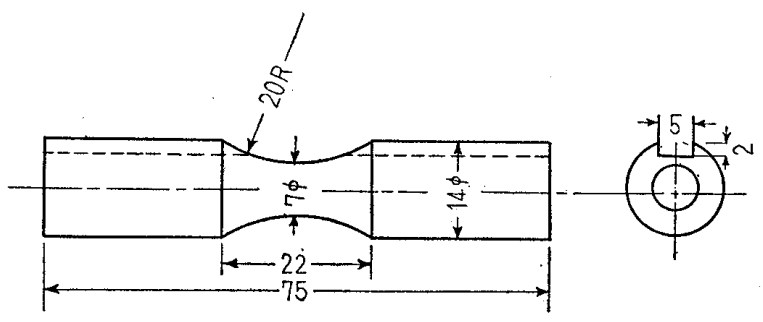

Fig. 1 Shape of test piece ally from the value of the moments settled shortly after starting of tests.

The town gas which is filled in the electric furnace to reduce the oxidation of the surface of test pieces was fully dried by passing it through SilicaGel. And the burning of the gas in the furnace was prevented by allowing the gas to flow into the furnace as much as possible to reduce the air content in the furnace. It was intended to remove sulphur in the town gas by activated carbons, but the effect of it might be unclear because of rather insufficient treatment.

The testing temperatures were $550^{\circ} \mathrm{C}$ and $400^{\circ} \mathrm{C}$, and the cyclic frequencies were 1810 c.p.m. and 240 c.p.m. The $S-N$ curves obtained are shown in Figs. 2 and 3 . In Fig. 3, the $S-N$ curve under 1810 c.p.m. at room temperature is also inserted.

The testing machine and material used in the present research are the same as those in the previous $\operatorname{paper}^{(3)}$, where the $S-N$ curves in air and in town gas were shown in Fig. 4 for $550^{\circ} \mathrm{C}, 1810$ c.p.m. In the tests, raw town gas was used, and the $S-N$ curves crossed each other clearly, showing the strength being lower in gas than in air under

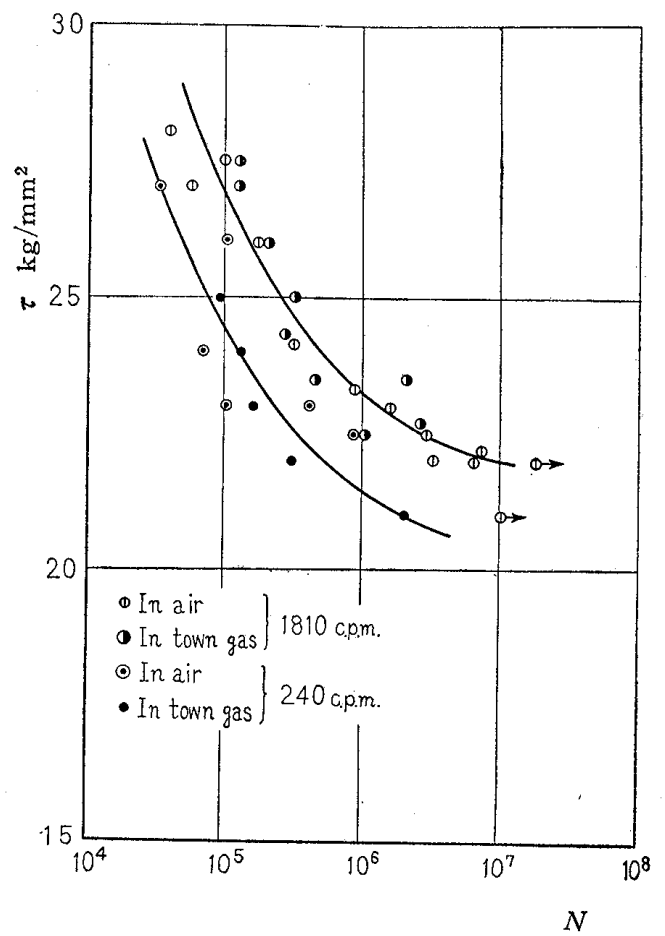

Fig. $2 S$ - $N$ diagram at $400^{\circ} \mathrm{C}$

Table 1 Chemical compositions and mechanical properties at the room temperature of the material used in the high temperature fatigue tests

\begin{tabular}{|c|c|c|c|c|c|c|c|c|c|}
\hline \multicolumn{4}{|c|}{ Chemical compositions \% } & \multirow{2}{*}{ Heat treatment } & \multicolumn{5}{|c|}{ Mechanical properties $\mathrm{kg} / \mathrm{mm}^{2}$} \\
\hline $\mathrm{C}$ & $\mathrm{Si}$ & $\mathrm{Mn}$ & $S$ & & $\sigma_{S}$ & $\sigma_{B}$ & $\sigma_{T}$ & $\delta$ & $\varphi$ \\
\hline 0.39 & 0.26 & 0.030 & 0.029 & $\begin{array}{l}\text { Air cooled from } \\
860^{\circ} \mathrm{C}, \quad 30 \mathrm{~min}\end{array}$ & 39.3 & 59.6 & 110.2 & 34 & 59 \\
\hline
\end{tabular}


high stress levels. The $S-N$ curve is, however, reformed as shown in Fig. 3 in the present paper, as a result of dehydration treatments of the town gas. Since the effect of water vapor was thus significant, fatigue tests in the town gas without dehydration treatment are added in the case of $550^{\circ} \mathrm{C}$ and 240 c.p.m. These results are shown in Fig. 4.

\section{Consideration on test results}

\subsection{Consideration with nominal stresses}

In the provious paper ${ }^{(3)}$, the author considered that the reason for the strength in gas being lower than in air for short life tests under high stresses may be embrittlement by nascent hydrogen, which is generated through the reaction between the high temperature steel and the water vapor contained in raw town gas and also formed by a burning of the gas. When the town gas is treated to remove moistures and the burning of the gas is prevented, the fatigue strengths in it become considerably higher than those in raw town gas, especially under high stress levels and under high cyclic frequencies as shown in Fig. 4. Consequently, as obvious in Fig. 3 , the $S-N$ curve in the town gas does not cross the one in air so remarkably as did the $S-N$ curve in the town gas without dehydration treatment shown in Fig. 4 in the previous paper.

It can be clarified from these facts that the consideration in the previous paper of the influence of water vapor on the high temperature fatigue is correct, and it may be known that the corrosion is

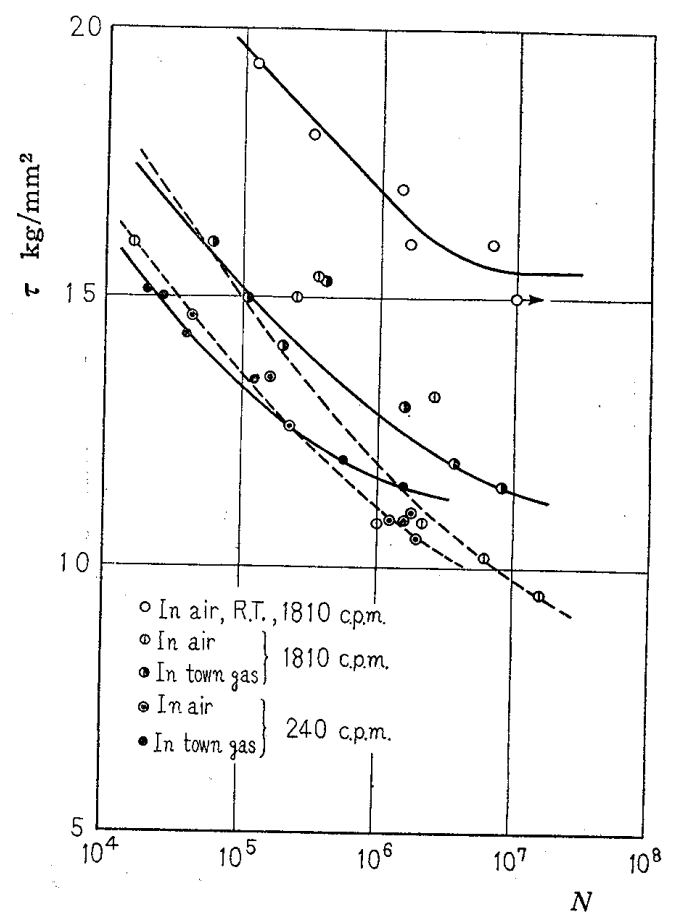

Fig. $3 S-N$ diagram at $550^{\circ} \mathrm{C}$ and at the room temperature slight in superheated steam containing little oxygen ${ }^{(6)}$, and that an oxide film made by heating a ferrous. alloy in steam is protective against the further penetration of hydrogen ${ }^{(9)}$. Whilst it is also suggested that the damage by water vapor appears under high stress levels where the hydrogen embrittlement becomes effective(10)(11), and that strain velocity affects the fracture of materials.

In $550^{\circ} \mathrm{C}$, the strength is distinctly higher in gas: than in air for long life test under low stress as indicated in Fig. 3. The phenomenon is due to the reduction of effect of corrosion fatigue by air oxidation, and the $S-N$ curves in gas in the present paper may be considered to represent the nearly true $S-N$ curves at elevated temperatures. The surfaces of specimens tested in the town gas were neither carbonized nor decarbonized, but were stained: slightly with soot under which a fine grey film covered the specimens tightly.

In the tests at $400^{\circ} \mathrm{C}$, the effect of the gas was. hardly observed under both cyclic frequencies as illustrated in Fig. 2. Accodingly, the effect of the corrosion fatigue by high temperature oxidation may be almost negligible for carbon steels at lower than $400^{\circ} \mathrm{C}$.

Regarding the effect of cyclic frequencies, the numbers of repetitions $N$ till rupture are less as. the frequency becomes lower at $400^{\circ} \mathrm{C}$ together with. at $550^{\circ} \mathrm{C}$. When the test results are indicated on. a stress-time basis, Figs. 5 and 6 are drawn. In. Fig. 5 of the tests at $400^{\circ} \mathrm{C}$, the time until rupture is longer for lower frequency under high stress levels, while reverse is the case under low stress levels. Both the $S$ - $t$ curves tend to cross each other.

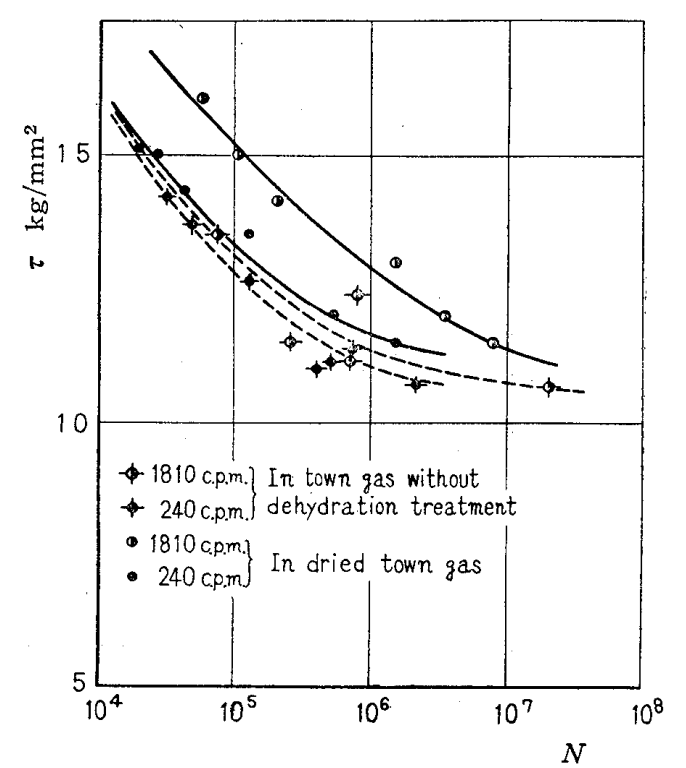

Fig. 4 The effect of dehydration treatment of the town gas on fatigue strengths at $550^{\circ} \mathrm{C}$ 
Although similar results have been obtained in the rotating bending fatigue tests of $0.17 \% \mathrm{C}$ carbon steel at $400^{\circ} \mathrm{C}$ by Forrest and Tapsel1 ${ }^{(1)}$, the reason is not made clear. It might be due to the higher strain velocity with higher stress level because the frequency effect in the temperature range of blue brittleness is known to be different from the frequency effect in the higher temperature ${ }^{(12)}$. Since, however, Fig. 5 shows rather large scatters of points, further tests may be expected in the range of low stress levels.

At $550^{\circ} \mathrm{C}$, the lives in air are clearly longer under lower frequency as shown in Fig. 6. The results are nearly in accord with the test results of Forrest and Tapsell(1). And it is characteristic of corrosion fatigue that repetition number till rupture is less and rupture time is longer when the cyclic frequency is lower ${ }^{(13)}$. In the test in town gas where the effect of corrosion fatigue due to high temperature oxidation is reduced, the rupture time seems only a little longer for lower frequency. The reason might be maximum stresses being lower under lower frequencies because of stress relaxation during a run in constant nominal stresses or constant twisting moments. Since, however, these $S-t$ curves coincide in a single curve with deviations in the range of experimental errors, the high temperature fatigue strengths are considered to be determined on the basis of the rupture time provided high temperature oxidation does not act as the corrosion fatigue. And the corrosion fatigue due

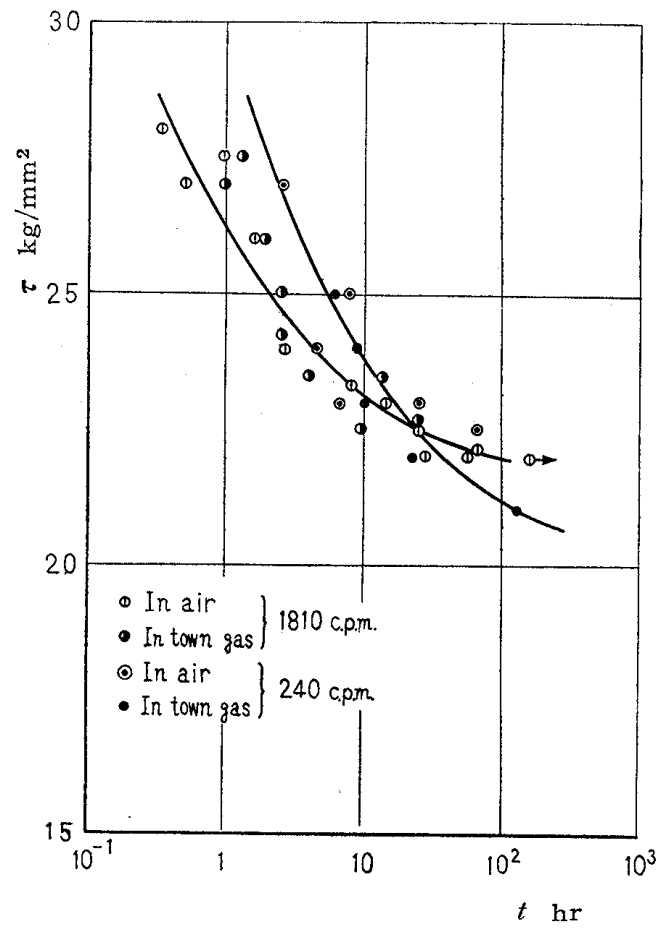

Fig. $5 S$ - $t$ diagram at $400^{\circ} \mathrm{C}$ to high temperature oxidation is found more severe under higher frequencies for the same duration.

$3 \cdot 2$ Consideration with plastic strains The high temperature fatigue is generally known to be discussed more reasonably and conveniently by using strain amplitudes rather than using stress amplitudes. Especially for the thermal fatigue, the amplitude of strain or plastic strain is the main subject. So, the strain amplitude $\gamma$ was measured for various amplitudes of nominal stresses $\tau$. The strain amplitudes are, as mentioned before, obtained from the differences of oscillating angles between both chucking elements for the test piece. Since the test piece has no parallel portion as shown in Fig. 1, the effective gage length to obtain the strain $\gamma$ is taken to the length of a bar assumed as follows ; The bar has a uniform sectional area which is the same as the minimum sectional area of the actual test piece. Then, the deformation of the bar is equalized to the elastic deformation of the actual test piece integrated over the whole length with consideration of the change of sectional area. The strain $\gamma$ obtained for room temperature, $400^{\circ} \mathrm{C}$, and $550^{\circ} \mathrm{C}$ by using the effective gage length above is shown in Fig. 7 in relation to the nominal stresses $\tau$. As the modulus of transverse elasticity is given by $G=8000 \mathrm{~kg} / \mathrm{mm}^{2}$ from the figure for room temperature, this conversion method of gage length is appropriate.

The amplitudes of plastic strain $\gamma_{p}$ are estimated from the elastic lines in the figure for various nominal stresses, though the value of $\gamma_{p}$ will unavoidablly

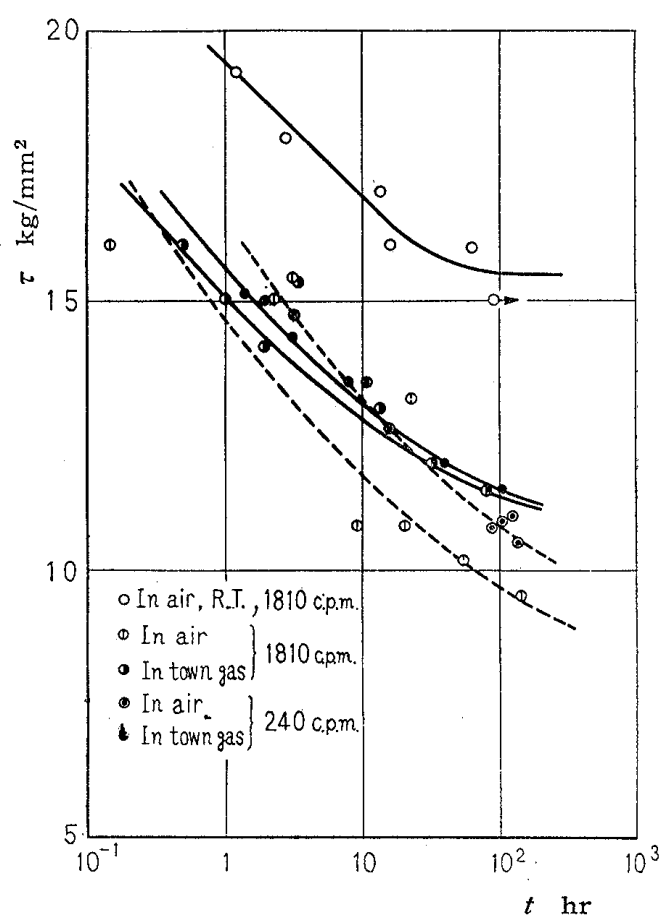

Fig. $6 S^{-} t$ diagran $\left.a t 55\right)^{\prime} \mathrm{C}$ and a $\mathrm{t}$ the room temperature 
have a little error since Fig. 7 is not the diagram for true stresses. The $\gamma_{p}-N$ curves thus obtained are shown in Fig. 8 for $550^{\circ} \mathrm{C}$ and the room temperature, and in Fig. 9 for $400^{\circ} \mathrm{C}$ respectively*.

It is reported by Coffin et $\mathrm{al}^{(14)}$ that the relation between the amplitude of plastic strain $\varepsilon_{p}$ and their repetition number $N$ till rupture in tension-compression are given by

$$
\varepsilon_{p} N^{\alpha}=K,
$$

where the exponent $\alpha$ is nearly equal to 0.5 and independent of the materials. In the paper and others on thermal fatigue, the frequencies of strain are very low and the amplitudes are large, and the discussions are limited within the repetition numbers less than $10^{5}$. For the present tests in the gas restraining the air oxidation at $550^{\circ} \mathrm{C}$, this relation covers a very wide range of $N$, and is expressed by

$$
\gamma_{p} N^{0.44}=K
$$

as shown in Fig. 8. In the air, as indicated by dotted lines in Fig. 8, the exponent of $N$ differs from the one in the town gas, and $\gamma_{p} N^{0.51}=0.95$ and $\gamma_{p} N^{0.62}=1.29$ are obtained respectively for 240 c.p.m. and 1810 c.p.m. This is considered to be attributed to oxidation of surfaces of the test pieces. Johanson $^{(15)}$ stated also that the $\mathrm{Cr}-\mathrm{Mo}$ steel which scaled very much during the test at $500^{\circ} \mathrm{C}$ had considerably lower strength than at $20^{\circ} \mathrm{C}$ and $300^{\circ} \mathrm{C}$ together with the cracks showing the general appearance of corrosion fatigue, although the allowable strain amplitudes of other heat resistant alloys were almost independent of temperatures for given cycles.

On the effect of cyclic frequency, it is stated in a report ${ }^{(2)}$ that rupture cycles do not vary by frequencies under a given plastic strain amplitude. But the present test results show less cycle num-

\footnotetext{
* The difference between $\gamma_{p}$ obtained from the nominal stress $\tau$ and $\tau_{p o}$ given by the true stress $\tau_{0}$ is shown schematically in the supplement. The true stresses $\tau_{0}$ of solid specimens under repeated twisting moments are estimated from Fig. 7, using Prandtl's formula $\tau_{0}=[3 M+\theta(d M / d \theta)] / 2 \pi r_{0}{ }^{3}$. The $\gamma_{p 0}-N$ diagrams are shown by straight lines having a little less inclination than Figs. 8 and 9 , but the general conclusions do not vary. The plastic strain amplitude $\gamma_{p}$ from the nominal stresses $\tau$ is taken, as $\tau_{0}$ is a value presumed.
}

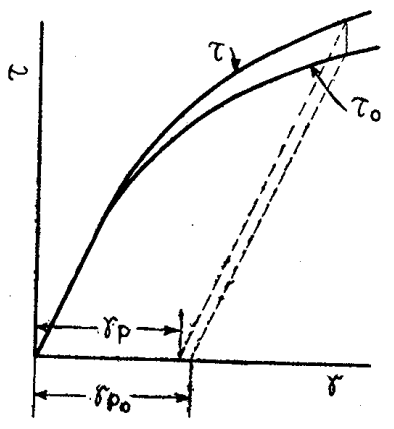

bers till rupture for the higher frequency.

Fig. 9 expresses the relation of $\gamma_{p} N^{0.44}=K$ existing also at $400^{\circ} \mathrm{C}$ for both the frequencies with some scatters of points, showing no effects of the environments. The strength is lower under higher frequency than under lower frequency in this case too, but the influence of cyclic frequency is less than at $550^{\circ} \mathrm{C}$.

At the room temperature, test results are a few and only for 1810 c.p.m. Nevertheless, the relation of $\gamma_{p} N^{0.44}=K$ is also obvious as indicated in Fig. 8. Since the effect of cyclic frequency is known to be but little in usual fatigue tests at the room temperature, the $\gamma_{p}-N$ curves for lower frequencies may overlap the one for 1810 c.p.m.

The values of $K$ in $\gamma_{p}-N$ curves are shown in

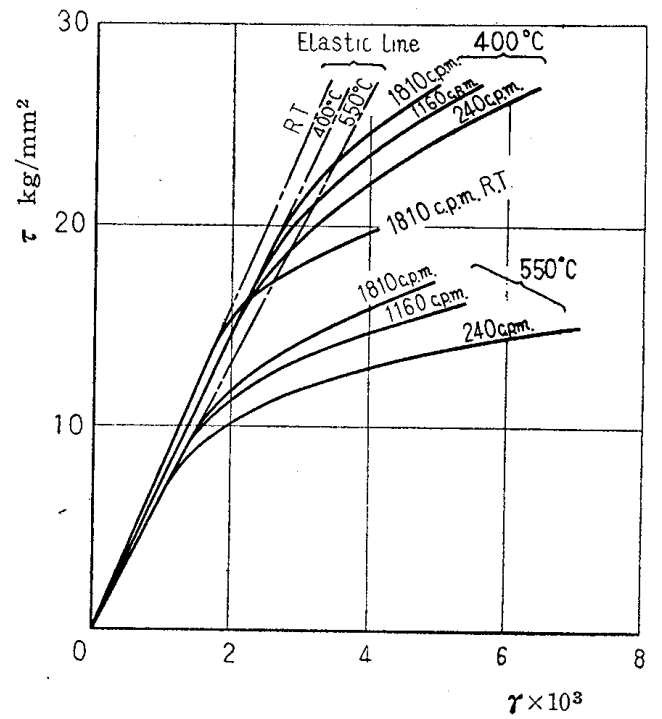

Fig. 7 The relation between the nominal stress and the strain amplitude

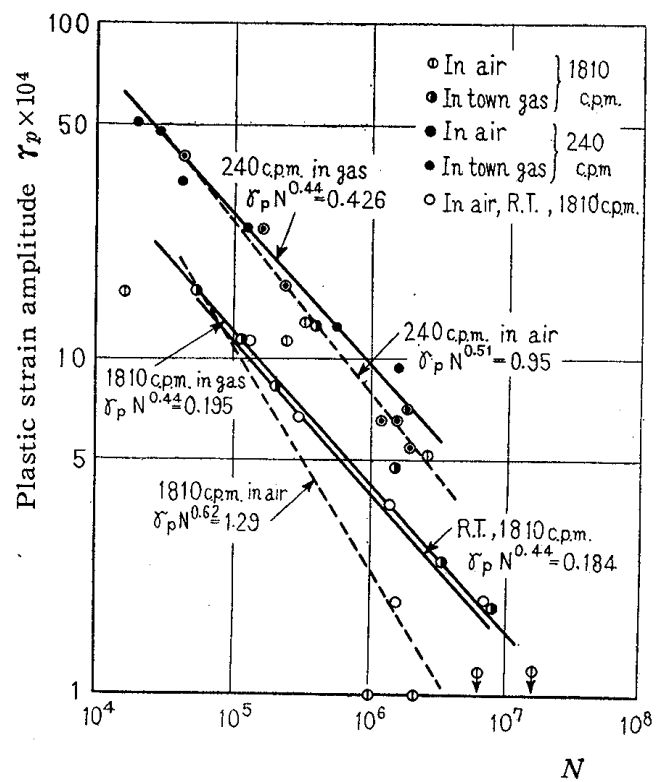

Fig. $8 \gamma_{p}-N$ diagram at $550^{\circ} \mathrm{C}$ and at the room temperature 
Fig. 10 against the cyclic frequencies and temperatures of each test with the reduced oxidation by using town gas. The frequency effect of $K$ value is considerable at high temperature, decreasing with the decrease of temperatures. And the effect of temperature on $K$ value is smaller for higher frequency than for lower frequency.

Although some paper(16) explained theoretically on the fracture by repeated plastic strain, the author makes a further attempt to induce the frequency effect. When the plastic strain is simply expressed by $\gamma_{p}=a \tau^{m} t^{n}$ ( $t$ : time, $a:$ constant), the plastic strain amplitude $\gamma_{p}$ under stresses repeated sinusoidally with angular velocity of $\omega$ is given by

$$
\gamma_{p}=a^{\prime} \tau^{m} \omega^{-n}
$$

where $a^{\prime}$ is a function of $n$. The relation between $\gamma_{p}$ and $\tau$ obtained from Fig. 7 is indicated in Fig. 11, showing good agreement with the above equation. The value of $m$ is $6 \sim 7$, and hardly varies by temperature and cyclic frequency. It is reported ${ }^{(17)}$ that

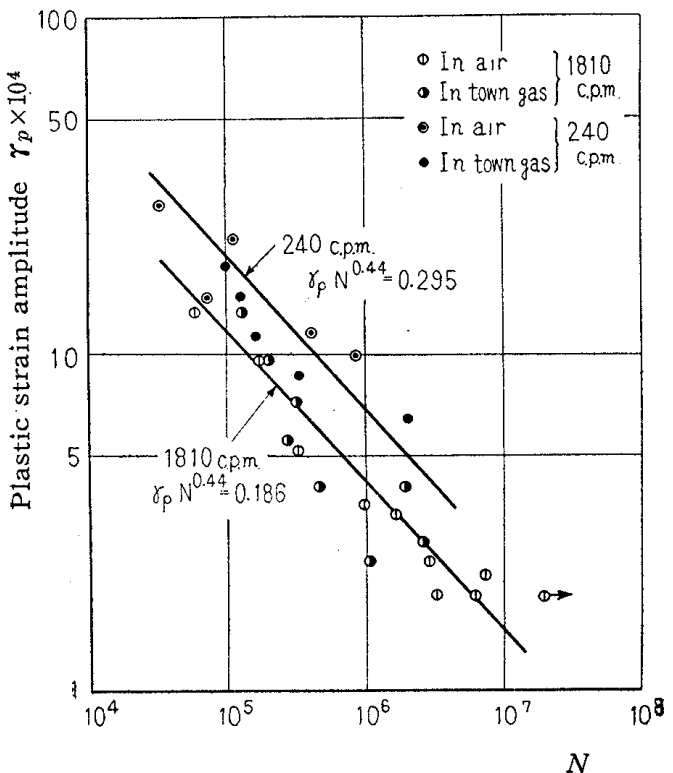

Fig. $9 \boldsymbol{\gamma}_{p}-N$ diagram at $400^{\circ} \mathrm{C}$

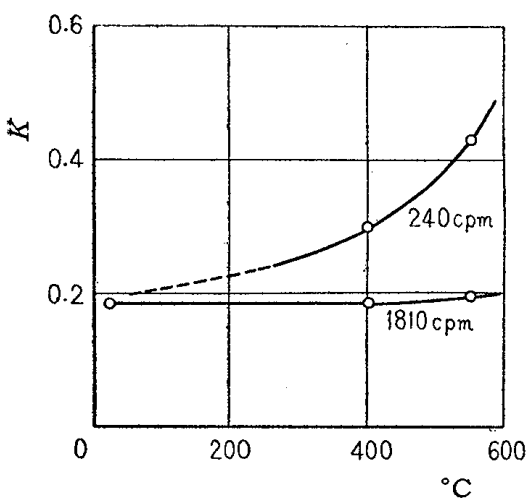

Fig. $10 K$ value in $\gamma_{p} N^{\alpha}=K$ obtained in the town gas vs. temperatures and cyclic frequencies $m$ is about 6 at the room temperature in the tests of various materials such as mild steel and brass. The value of $n$ is found to decrease with lowering temperatures.

The energy loss during a cycle becomes

$$
w=2 \int_{0}^{r_{p}} \tau d \Upsilon_{p}=a^{\prime \prime} \gamma_{p}^{(m+1) / m} \omega^{1 / m} \text {. }
$$

In practice, the energy loss would not contribute to the fatigue damage in the above form. Nevertheless,

$$
\gamma_{p} N^{m /(m+1)}=c \omega^{-n /(m+1)}
$$

may be obtained under the assumption that the fatigue failure occurs when the product of $w_{p}$ and $N$ reaches a given value, where $c$ is a function of $m$ and $n$. This equation, though estimated roughly, may explain the quality of $\gamma_{p} N^{\alpha}=K$ mentioned above where the exponent $\alpha$ does not vary with the test conditions and the value of $K$ depends on temperatures and cyclic frequencies as shown in Fig. 10 .

It was reported by Swindeman and Douglas ${ }^{(18)}$ that Inconel had a little larger repetition number till rupture under higher cyclic frequency. The frequency effect was less than that of the present test results and it may be due to the difference of condition of energy loss, since the tests by Swindeman and Douglas was the repetition of strains held at a constant value during a given time.

These yield the following conclusion on the $\gamma_{p}-N$ curve. Although the frequency effect is hardly found at the room temperature, it becomes more remarkable when the test temperature is higher. The $\gamma_{p}-N$ curve takes upper position under the condition of lower frequency comparing with one under higher frequency. These curves lie in parallel to each other with the constant value of $\alpha$ in the town gas.

When the cyclic frequency becomes sufficiently high, the $\gamma_{p}-N$ curve is almost independent of test temperatures.

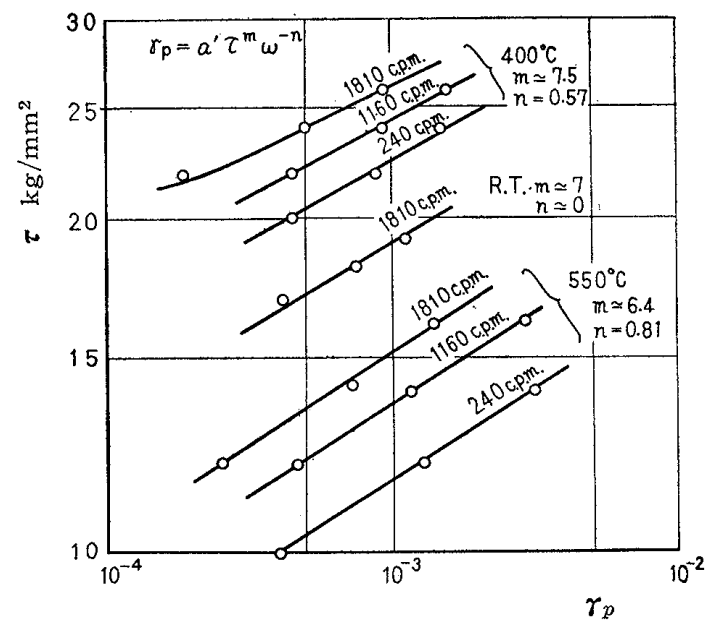

Fig. 11 The relation between plastic strain amplitude $\gamma_{p}$ and nominal stress amplitude $\tau$ 


\section{Conclusions}

Torsional fatigue tests of a carbon steel were carried out under the condition of 1810 , and 240 c.p.m. and at $550^{\circ}, 400^{\circ} \mathrm{C}$, and the room temperature. The test environments were the air and the town gas to reduce air oxidation at elevated temperatures. As a result of the tests, the following has been found:

(1) The tests in raw town gas show considerably lower strength, especially under high stress level and high frequency, than in the town gas which is treated to remove moistures. This is considered to be due to the embrittlement by nascent hydrogen which is generated through the high temperature steel-steam reaction. All the subsequent tests were made in the dehydrated town gas.

(2) At $550^{\circ} \mathrm{C}$, the strength is higher in gas than in air for long life tests under low stress levels. The fact is due to the reduction of corrosion fatigue effect by high temperature oxidation. The repetition numbers till rupture are less under lower frquency than under higher frequency both in the air and in the gas. When the results are indicated on a stress-time basis, $S$ - $t$ curves in gas lie approximately on a single curve for different frequencies, and time till rupture is hardly affected by cyclic frequency. In the air, however, the rupture time is shorter under higher frequency than under lower frequency, and the influence of corrosion fatigue is clearly observed.

(3) At $400^{\circ} \mathrm{C}$, the rupture cycles are less under lower frequency than under higher frequency, and no effect of the gas is found in the $S-N$ curves. The rupture time is longer at lower frequency than at higher frequency under high stress levels, while reverse is the case under low stress levels, and both the $S$ - $t$ curves tend to cross each other.

(4) When the results described above are indicated by a relation between the amplitude of plastic strain $\gamma_{p}$ and the cycles to rupture $N$,

$$
\gamma_{p} N^{\alpha}=K
$$

is obtained under all test conditions.

(5) The frequency effect is scarcely found in the $\gamma_{p}-N$ curves at the room temperature, but it appears much more at higher temperatures, and the
$\gamma_{p}-N$ curve of lower frequency lies on upper side of that of higher frequency. And these curves run parallel to each other with the constant value of $\alpha$ in the town gas to reduce air oxidation. When the cyclic frequency becomes sufficiently high, the $\gamma_{p}-N$ curve is almost independent of test temperatures.

(6) In the air, however, $\gamma_{p}-N$ curves deviate from the straight line in the town gas, showing a decrease of strength, because of progress of corrosion fatigue effect by high temperature oxidation.

\section{Acknowledgments}

Thanks are due to the Education Ministry for allocation of the Science Research Funds for the present research. The author would like to thank also Messrs. Y. Miyao, I. Matsune, and K. Miura for substantial assistance in experiments.

\section{References}

(1) P.G. Forrest and H.J. Tapsell : Proc. Inst. Mech. Engr., Vol. 163 (1954), p. 763.

(2) T. Nishihara, S. Taira, K. Tanaka, R. Koterazawa, and Y. Azuma: Trans. Japan Soc. Mech. Engrs., Vol. 24, No. 143 (1958), p. 452.

(3) K. Endo: Bulletin of JSME, Vol. 3, No. 9 (1960), p. 76 .

(4) G.J. Danek, Jr. and M.R. Achter : Bull. ASTM, No. 234 (1958), p. 48.

(5) J.R. Bohn and G. Murphy: Bull, ASTM, No. 234 (1958), p. 57.

(6) A.H. Goodger: Intern. Conf. on Fatigue of Metals (1956), p. 394.

(7) J. de Fouquet, R. Jacquesson, et P. Laurent : Rev. Mét., Vol. 57, No. 1 (1960), p. 62.

(8) R. Cazaud : Fatigue of Metals (1953), p. 196, Chapman and Hall Ltd.

(9) C.A. Zapffe and F.K. Landgraf : ASTM, STP No. 108 (1955), p. 50.

(10) G. Schevan, G. Sachs, and K. Tong : Proc. ASTM, Vol. 57 (1957), p. 682 .

(11) J.S. Jackson: Intern. Conf. on Fatigue of Metals: (1956), p. 500 .

(12) P.G. Forrest: Proc. Roy. Soc. Lond., Sec. A, Vol. 242 (1957), p. 223.

(13) K. Endo and Y. Miyao : Bulletin of JSME, Vol. 1, No. 4 (1958), p. 374.

(14) E.E. Baldwin, G.J. Sokol, and L.F. Coffin, Jr.: Proc. ASTM, Vol. 57 (1957), p. 567.

(15) A. Johanson: Col. on Fatigue, IUTAM (1955), p. 112 .

(16) S. Taira and R. Koterazawa : Bulletin of JSME, Vo1. 3, No. 10 (1960), p. 235.

(17) Y. Takenaka: Trans. Japan Soc. Mech. Engrs., Vol. 26, No. 161 (1960), p. 102.

(18) R.W. Swindeman and D.A. Douglas: Trans. ASME, Ser. D, Vol. 81, No. 2 (1959), p. 203. 